\title{
Mathematical Model of Sulfide Precipitation on Oxides during Solidification of Fe-Si Alloy
}

\author{
Zhongzhu LIU, Kejing GU ${ }^{1)}$ and Kaike CAI ${ }^{21}$ \\ Formerly graduate Student, Institute of Steelmaking, Metallurgical Engineering School, University of Science and Technology \\ Beijing, Beijing 100083 China. Now at Metallurgical Processing Group, Steel Research Center, National Institute for Materials \\ Science, Sengen, Tsukuba, Ibaraki 305-0047 Japan. E-mail: LIU.Zhongzhu@nims.go.jp \\ 1) Graduate Student, Institute of Steelmaking, Metallurgical Engineering School, University of Science and Technology \\ Beijing, Beijing 100083 China. $\quad$ 2) Institute of Steelmaking, Metallurgical Engineering School, University of Science and \\ Technology Beijing, Beijing 100083 China. E-mail:kaikecai@metall.ustb.edu.cn
}

(Received on January 21, 2002; accepted in final form on May 31, 2002)

\begin{abstract}
A mathematical model of sulfide precipitation on oxides during solidification is established based on the coupled model of microsegregation and inclusion precipitation, which is also established by the present authors. ${ }^{1)}$ In this paper, sulfide capacity and optical basicity are introduced to calculate the distribution of sulfur between liquid oxides and molten steel during solidification, and the effect of composition of oxides on the precipitation of sulfide is also discussed. The calculated results agree well with the experiment results and data reported.
\end{abstract}

KEY WORDS: solidification; microsegregation; oxide metallurgy; mathematical model; sulfide precipitation; sulfide capacity; basicity.

\section{Introduction}

Oxide metallurgy, the technology to modify inclusion for optimal product properties, has been recommended as a means to control steel properties via effective utilization of fine oxides as heterogeneous nucleation sites for transformation and precipitation. ${ }^{2-4)}$ Sulfide precipitated during solidification is also important for the formation of GOSS texture in oriented silicon steels. Lots of works about the sulfide precipitated on oxides and mathematical simulating models were reported. ${ }^{5-10)}$ But the mechanism about sulfide precipitation on oxides is not very clear yet.

In this paper, a mathematical model of sulfide precipitated on oxides during solidification is presented based on a microsegregation model. The coupled calculations of microsegregation of solute elements and inclusion precipitation are carried out and the precipitation of oxides and sulfides can be calculated simultaneously in the model. Sulfide capacity and optical basicity are introduced to calculate the distribution of sulfur between liquid oxides and molten steel, and the effect of composition of oxides on the precipitation of sulfide during solidification is discussed. The calculated results agree well with the experiment results and data reported.

\section{Mathematical Model}

\subsection{Coupled Model of Microsegregation and Inclusion Precipitation}

The same coupled mathematical model used in our previous work ${ }^{1)}$ was used to interpret the results of redistribution of solute elements and precipitation of oxides and sulfides from liquid steel during solidification. With this model, the distribution of solute elements, the precipitation of oxides and sulfides from liquid steel can be calculated simultaneously. The model takes into account a partial diffusion of alloying elements in solid phase and is based on the following assumptions:

(1) The geometry of the solid/liquid interface is plane.

(2) The calculation domain corresponds to the half secondary dendrite spacing.

(3) The temperature is uniform in the space element.

(4) The density of the liquid is equal to that of the solid.

(5) The composition of the liquid is uniform and the thermodynamic equilibrium is realized at the solid/liquid interface.

(6) A parabolic growth rate is assumed.

One-dimensional diffusion of seven elements (C, Si, Mn, $\mathrm{P}, \mathrm{S}, \mathrm{Al}$, and $\mathrm{O}$ ) is calculated by using different diffusion coefficients in solid phase. The calculation is carried out by the direct finite difference method. Half area of the secondary dendrite spacing is divided into $N$ nodes. The segregation of solute elements in molten and solid steel during solidification can be calculated with the following equations.

At time $t$, in the solid phase $(1<i<m)$

$$
\frac{C_{i}^{t}-C_{i}^{t-\Delta t}}{\Delta t}=D \cdot \frac{C_{i+1}^{t-\Delta t}-2 \cdot C_{i}^{t-\Delta t}+C_{i-1}^{t-\Delta t}}{\Delta x^{2}}
$$

Where $C_{i}^{t}$ is the concentration of solute elements in weight percent in nodal $i$ at time $t, D$ is diffusion coefficient in 
solid phase.

at the node $i=1$

$$
\frac{C_{i}^{t}-C_{i}^{t-\Delta t}}{\Delta t}=D \cdot \frac{C_{i+1}^{t-\Delta t}-C_{i}^{t-\Delta t}}{\Delta x^{2}}
$$

on the solid/liquid interface $(i=m)$

$$
C_{m}^{t}=C_{\mathrm{L}}^{t} \cdot k^{\delta / \mathrm{L}}
$$

Where $k^{\delta / L}$ is the partition coefficient of solute elements between liquid and solid ( $\delta$ phase).

The following equation can be derived from a mass balance.

$$
N \cdot C_{\mathrm{L}}^{0}=\sum_{i=1}^{m} C_{i}^{t}+(N-m) \cdot C_{\mathrm{L}}^{t}
$$

Where $C_{\mathrm{L}}^{0}$ is the initial solute concentration.

Combining Eqs. (1)-(4), the following equations can be obtained.

$$
\begin{gathered}
C_{\mathrm{L}}^{t}=\frac{N \cdot C_{\mathrm{L}}^{0}-\sum_{i=1}^{m-1} C_{i}^{t-\Delta t}+F^{\prime} \cdot C_{m-1}^{t-\Delta t}}{(N-m)+\left(1+F^{\prime}\right) \cdot k^{\delta / \mathrm{L}}} \\
C_{m}^{t}=\frac{N \cdot C_{\mathrm{L}}^{0}-\sum_{i=1}^{m-1} C_{i}^{t-\Delta t}+F^{\prime} \cdot C_{m-1}^{t-\Delta t}}{(N-m) / k^{\delta / \mathrm{L}}+1+F^{\prime}}
\end{gathered}
$$

where

$$
F^{\prime}=\frac{D \cdot \Delta t}{\Delta x^{2}}=\frac{4 \cdot D \cdot t_{\mathrm{s}}}{L^{2}} \cdot N^{2} \cdot\left(\left(f_{\mathrm{s}}^{t}\right)^{2}-\left(f_{\mathrm{s}}^{t-\Delta t}\right)^{2}\right)
$$

and $f_{\mathrm{s}}^{t}$ is the solid fraction at time $t, L$ is the secondary dendrite spacing, $t_{\mathrm{s}}$ is the local solidification time of steel.

It is assumed that the oxides are uniformly dispersed in the specimen. With segregation during steel solidification, new non-metallic inclusions precipitate and grow when the segregated solute elements exceed the equilibrium value. The precipitation of inclusion, taking $\mathrm{MnS}$ as an example, starts immediately after the product of $\mathrm{Mn}$ and $\mathrm{S}$ contents in solution reaches the equilibrium solubility limit in each phase. Between $\mathrm{MnS}$ and iron, these two phases are in equilibrium.

The calculation of inclusion precipitation is based on the materials balance expressed at each instant for each solute element by the following relationship:

For Mn,

$$
\sum_{i=1}^{N} C_{\mathrm{L}, \mathrm{Mn}}^{0}=\sum_{i=1}^{m} C_{i, \mathrm{Mn}}^{t}+(N-m) \cdot C_{\mathrm{L}, \mathrm{Mn}}^{t} \sum_{i=1}^{m} \operatorname{Cin}_{i, \mathrm{Mn}}^{t} \cdot(N-i+1)
$$

For $\mathrm{S}$,

$$
\sum_{i=1}^{N} C_{\mathrm{L}, \mathrm{S}}^{0}=\sum_{i=1}^{m} C_{i, \mathrm{~S}}^{t}+(N-m) \cdot C_{\mathrm{L}, \mathrm{S}}^{t} \sum_{i=1}^{m} \operatorname{Cin}_{i, \mathrm{~S}}^{t} \cdot(N-i+1)
$$

Where Cin is the consumption of solute elements (for example, $\mathrm{Mn}$ or $\mathrm{S}$ ) due to inclusion precipitation from time $t-d t$ to time $t$ during solidification.

From time $t-d t$ to time $t$, nodal $i$ solidifies and the consumption of solute elements due to inclusion precipitation in nodal $i$ are assumed to be equal to that in the molten steel in the present model.

At the same time, in molten steel,

$$
\begin{aligned}
& C_{\mathrm{L}, \mathrm{Mn}}^{t} \cdot f_{\mathrm{Mn}} \cdot C_{\mathrm{L}, \mathrm{S}}^{t} \cdot f_{\mathrm{S}}=K_{\mathrm{L}, \mathrm{MnS}} \\
& \operatorname{Cin}_{i, \mathrm{~S}}^{t} \cdot 54.94=\operatorname{Cin}_{i, \mathrm{Mn}}^{t} \cdot 32.06
\end{aligned}
$$

Where 54.94 and 32.06 are the atomic weights of S and Mn respectively, $f_{\mathrm{S}}$ and $f_{\mathrm{Mn}}$ are the activity coefficients of $\mathrm{S}$ and Mn in molten steel respectively and can be calculated using Eq. $(11)^{11)}$.

$$
\log f_{i}=e_{i}^{i}[\% i]+\sum e_{i}^{j}[\% j]
$$

Based on Turkdogan's data, ${ }^{11)}$ Eq. (12) was induced to calculate the value of $f_{\mathrm{S}}^{\mathrm{Si}}$ for the mass concentration of silicon above $1 \%$.

$$
f_{\mathrm{S}}^{\mathrm{Si}}=0.3067[\% \mathrm{Si}]+0.72 .
$$

The data used in the thermodynamic calculation are listed in Tables $\mathbf{1}^{5,10)}$ and 2. ${ }^{7,12)}$

Combining Eqs. (1)-(12), the concentration of each solute element and the amount of precipitated $\mathrm{MnS}$ can be calculated during solidification. The precipitation of oxides are treated just in the same manner as the precipitation of $\mathrm{MnS}$ from molten steel, and the concentration of oxygen in molten steel is assumed to be in equilibrium with the strong deoxidizer. That means, for example, when the reaction between $\mathrm{SiO}_{2}$ and $\mathrm{Al}_{2} \mathrm{O}_{3}$ occurs, mullite $\left(3 \mathrm{Al}_{2} \mathrm{O}_{3} \cdot 2 \mathrm{SiO}_{2}\right)$ precipitates and oxygen is in equilibrium with both $\mathrm{Al}$ and $\mathrm{Si}$ at the same time in molten steel. In that case, the concentration of oxygen in equilibrium with both $\mathrm{Al}$ and Si must be

Table 1. Equilibrium distribution coefficients and diffusion coefficients of solutes in iron.

\begin{tabular}{|c|c|c|c|}
\hline \multirow{2}{*}{ element } & \multicolumn{2}{|c|}{$\mathrm{D}_{\mathrm{s}}, \times 10^{-4} \mathrm{~m}^{2} / \mathrm{s}$} & \multirow{2}{*}{$k^{\delta / L}$} \\
\cline { 2 - 3 } & $\mathrm{D}_{\mathrm{O}}$ & $\mathrm{Q}, \mathrm{J} / \mathrm{mol}$ & \\
\hline $\mathrm{C}$ & 0.0127 & -81301 & 0.19 \\
\hline $\mathrm{Si}$ & 8.0 & -248710 & 0.77 \\
\hline $\mathrm{Mn}$ & 0.76 & -116935 & 0.77 \\
\hline $\mathrm{P}$ & 2.9 & -229900 & 0.23 \\
\hline $\mathrm{S}$ & 4.56 & -214434 & 0.05 \\
\hline $\mathrm{Al}$ & 5.9 & -241186 & 0.6 \\
\hline $\mathrm{O}$ & 0.0371 & -96349 & 0.03 \\
\hline
\end{tabular}

where $\quad D_{s}=D_{0} * \exp (Q / R T) \quad R=8.306 \mathrm{~J} / \mathrm{mol} \quad \mathrm{K}$

Table 2. Activity interaction parameters at $1873 \mathrm{~K} .{ }^{9,15)}$

\begin{tabular}{|c|c|c|c|c|c|c|c|}
\hline$e_{i}^{j}(\mathrm{j})$ & $\mathrm{C}$ & $\mathrm{Si}$ & $\mathrm{Mn}$ & $\mathrm{P}$ & $\mathrm{S}$ & $\mathrm{Al}$ & $\mathrm{O}$ \\
\hline $\mathrm{Si}$ & 0.18 & 0.103 & -0.0146 & 0.09 & 0.066 & 0.058 & -0.119 \\
\hline $\mathrm{Mn}$ & -0.0538 & -0.0327 & 0 & -0.06 & -0.048 & 0.027 & -0.087 \\
\hline $\mathrm{Al}$ & 0.091 & 0.056 & 0.035 & 0.033 & 0.035 & 0.043 & -1.98 \\
\hline $\mathrm{O}$ & -0.42 & -0.066 & -0.0224 & 0.07 & -0.133 & -1.17 & -0.17 \\
\hline $\mathrm{S}$ & 0.112 & 0.063 & -0.026 & 0.29 & -0.028 & 0.035 & -0.27 \\
\hline
\end{tabular}


less than that in equilibrium with $\mathrm{Al}$ or Si respectively.

The studied silicon alloy in this paper has a composition of $0.04 \% \mathrm{C}, 3.0 \% \mathrm{Si}, 0.058 \% \mathrm{Mn}, 0.01 \% \mathrm{P}, 0.022 \% \mathrm{~S}$, $0.0022 \% \mathrm{Al}$ and $0.0010 \% \mathrm{O}$. According to $\mathrm{Fe}-\mathrm{Si}$ phase diagram, there is no $\delta / \gamma$ transformation from liquid to solid if the composition of carbon is less than $0.1 \%$ in silicon alloy.

\subsection{Sulfide Precipitation on Oxides}

2.2.1. Mechanism of Sulfide Precipitation on Oxides during Solidification

With the development of oxide metallurgy, several mechanisms of the nucleation of $\mathrm{MnS}$ precipitated on oxides were proposed by M. Wakoh, ${ }^{13)} \mathrm{K}$. Oikawa ${ }^{14)}$ and Z. Ma et al. ${ }^{15)}$ However, there is still uncertainty with regard to the mechanisms proposed by them. In this paper, more reasonable and accurate mechanism of sulfide precipitation on oxides in steel is outlined.

In the present model, $\mathrm{S}$ is dissolved in liquid oxides in steel at high temperatures and during solidification and reaches its equilibrium distribution between molten steel and liquid oxides.

During solidification, $\mathrm{S}$ is redistributed between solid and molten steel. At the same time, $\mathrm{S}$ is also redistributed between molten steel and liquid oxides. That means, with the segregation of $\mathrm{S}$ in molten steel, the content of $\mathrm{S}$ dissolved in liquid oxides also increases according to the equilibrium distribution ratio of sulfur between oxide and metal unless the content of $\mathrm{S}$ dissolved in liquid oxides exceeds the saturated solubility of $\mathrm{S}$ in oxides.

As the temperature decreases the solubility of $\mathrm{MnS}$ in oxides decreases. At the same time, the product of $\mathrm{Mn}$ and $\mathrm{S}$ contents in molten steel and liquid oxides increases gradually due to the segregation in molten steel during solidification. MnS crystallizes when the product of $\mathrm{Mn}$ and $\mathrm{S}$ contents reach the equilibrium solubility limit in steel or oxides. After the complete solidification of the steel, with the temperature decreasing $\mathrm{MnS}$ precipitates from liquid oxides due to the decrease of the solubility in oxides until oxides solidify. After oxides solidify, the precipitation of $\mathrm{MnS}$ from oxides is neglected in the present model.

\subsubsection{The Equilibrium Oxide-Metal Sulfur Distribution Ratio}

In the present model, liquid oxides in molten steel are treated as oxide slag system. The sulfide capacity of a slag is usually defined by the equation,

$$
C_{\mathrm{S}}=(\% \mathrm{~S})\left(\frac{p_{\mathrm{O}_{2}}}{p_{\mathrm{S}_{2}}}\right)^{1 / 2}
$$

According to I. D. Sommerville's report, ${ }^{16)}$ sulfide capacity and the equilibrium slag-metal sulfur distribution can be related by the following equation.

$$
\log \frac{(\% \mathrm{~S})}{\alpha_{[\mathrm{S}]}}=-\frac{770}{T}+1.30+\log C_{\mathrm{S}}-\log \alpha_{[\mathrm{O}]}
$$

Where $a_{[\mathrm{S}]}$ and $a_{[\mathrm{O}]}$ represent Henrian activity of sulfur and oxygen in liquid with respect to hypothetical $1 \mathrm{wt} \%$ solution respectively.

The effect of slag composition and temperature can be

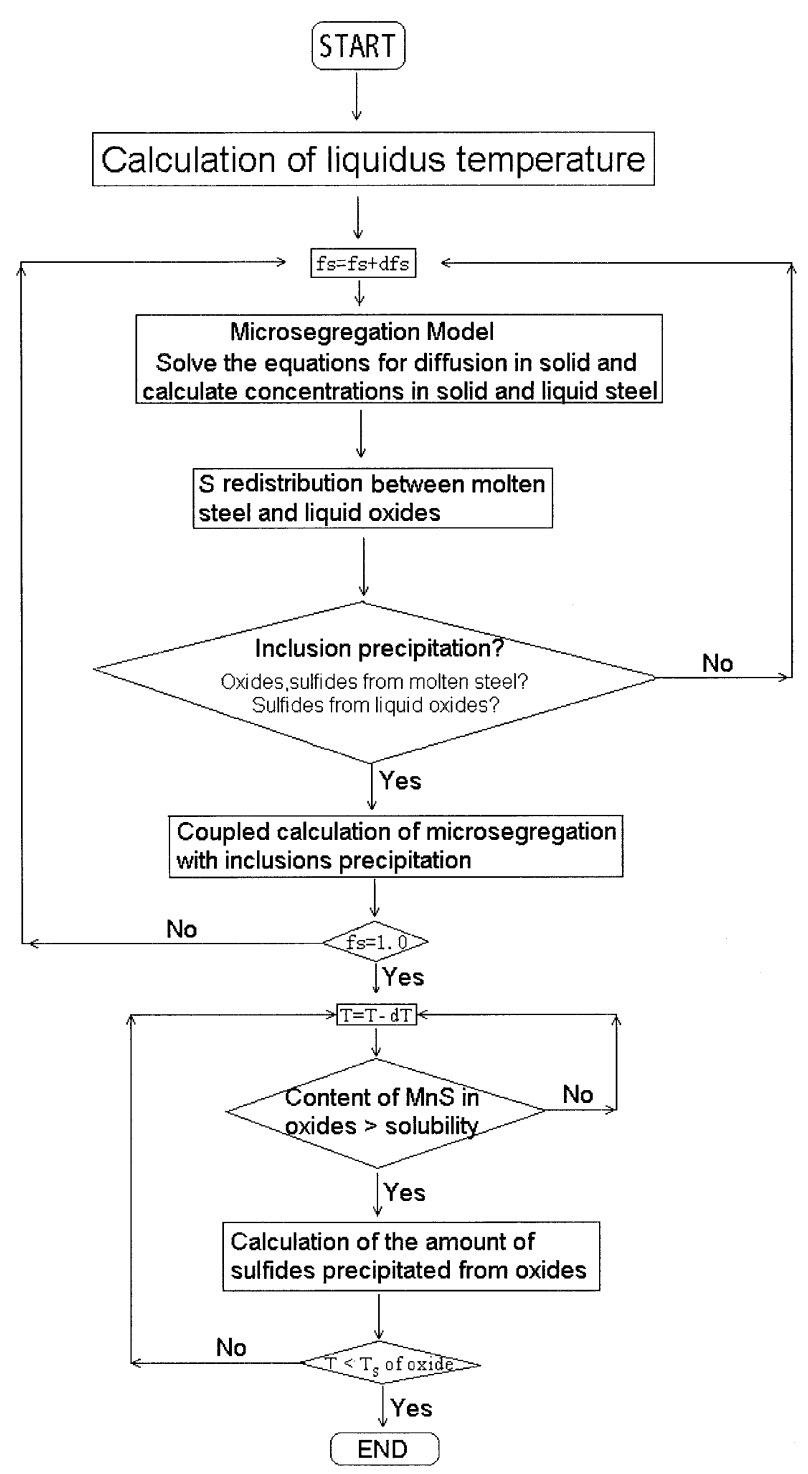

Fig. 1. Flow chart for the calculation of solute distribution and inclusion precipitation.

combined in the following equation.

$$
\log C_{\mathrm{S}}=\frac{22690-54640 \cdot \Lambda}{T}+43.6 \Lambda-25.2
$$

Where $\Lambda$ is the optical basicity of slag.

Use of Eq. (15) allows calculation of the sulfur capacity of an oxide slag of any composition at any temperature between $1400^{\circ} \mathrm{C}$ and $1700^{\circ} \mathrm{C}$.

Substitution of Eq. (15) into Eq. (14) yields an equation express the equilibrium sulfur distribution ratio in terms of temperature and the optical basicity of the slag.

$$
\log \frac{(\% \mathrm{~S})}{\alpha_{[\mathrm{S}]}}=\frac{21920-54640 \Lambda}{T}+43.6 \Lambda-23.9-\log \alpha_{[\mathrm{O}]}
$$

Hence, the equilibrium distribution of sulfur between oxide slag (oxide) and metal can be calculated.

\subsubsection{Flow Chart of the Present Model}

The flow chart of the present model is shown in Fig. 1. The factors taken into account in the present model are as 
follows:

(1) The precipitation of oxides and sulfides from molten steel.

(2) The redistribution of S between molten steel and oxides existing before solidification and precipitating during solidification.

(3) The precipitation of MnS from oxides.

\section{Result and Discussion}

\subsection{Sulfide Precipitation on Oxide during Solidification}

The effects of composition of oxides, which may exist before solidification or precipitate during solidification, on the precipitation of sulfide during solidification discuss as follows. Provided there exists an oxide with radius of five micrometer and composition of $30 \% \mathrm{Al}_{2} \mathrm{O}_{3}, 30 \% \mathrm{SiO}_{2}$, $15 \% \mathrm{MnO}, 25 \% \mathrm{FeO}$ in molten steel before steel solidification, which is the most common composition of oxide in $\mathrm{Fe}-\mathrm{Si}$ alloy studied, and it is not engulfed into solid phase until the end of steel solidification. The steel has the same composition of $\mathrm{Fe}-\mathrm{Si}$ alloy studied above.

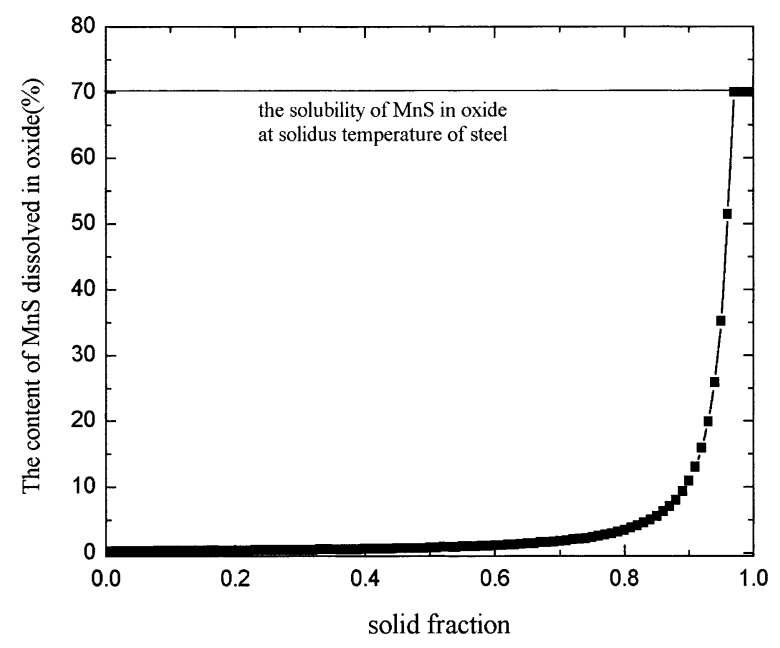

Fig. 2. The content of MnS dissolved in oxide versus solid fraction during solidification.
The calculated change of dissolved MnS content in this oxide during solidification of the steel is shown in Fig. 2. With the development of solidification, the content of dissolved $\mathrm{MnS}$ in oxide increases and at the end of solidification it reaches its saturated solubility in oxide.

After the solidification of steel, with the temperature decreasing the solubility of sulfide in oxide decreases. The content of sulfide in oxide exceeds the solubility of sulfide in oxide and sulfide precipitates from oxide continuously, which is shown as Fig. 3.

\subsection{Sulfide Precipitation from Oxides Engulfed into Solid Phase at Different Time}

During solidification of steel, oxides could be engulfed into solid phase continuously. Supposing there exist three oxides (oxide I, B, and A) with the same composition. These oxides are engulfed in solid phase at different solid fraction $\left(f_{\mathrm{s}}=0.9,0.95\right.$ and 1.0 respectively as shown in Fig. 4).

For oxide I, only when the temperature decreases to point $\mathrm{K}$, the content of $\mathrm{MnS}$ in oxide I begins to exceed the solubility of $\mathrm{MnS}$ in oxide I. Some MnS start to precipitate from oxide I and the precipitation amount of MnS changes along with curve KL. The precipitation stops at the solidus temperature of oxide. For oxide B, when temperature decreases to point $\mathrm{G}$, some $\mathrm{MnS}$ begin to precipitate from it and the precipitation amount of $\mathrm{MnS}$ changes along with curve GH. For oxide A, MnS precipitates immediately after steel solidification and the precipitation amount of $\mathrm{MnS}$ changes along with curve MN.

It is clear that, for the same composition oxides, the latter the oxide engulfed into solid phase, the higher the content of $\mathrm{MnS}$ dissolved in oxide, and the larger the amount of MnS precipitated from oxide.

\subsection{The Effect of Composition of Oxides on the Precipitation of Sulfide}

The different precipitation behavior of MnS from two oxides with different composition shown in Table 1 is studied. The reports of the data of solubility of $\mathrm{MnS}$ in different oxide slag system are very few and limited to two or three

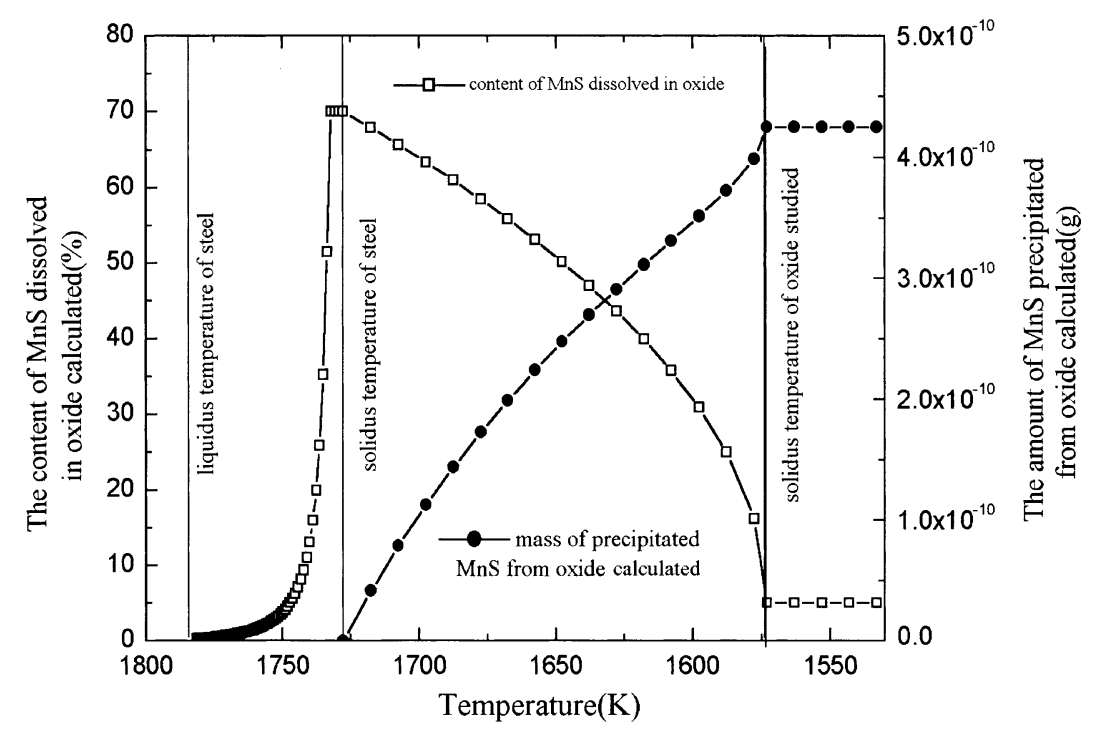

Fig. 3. The precipitation of MnS from oxide versus temperature during solidification. 
The mass of $\mathrm{MnS}$ in oxides $(\mathrm{g})$

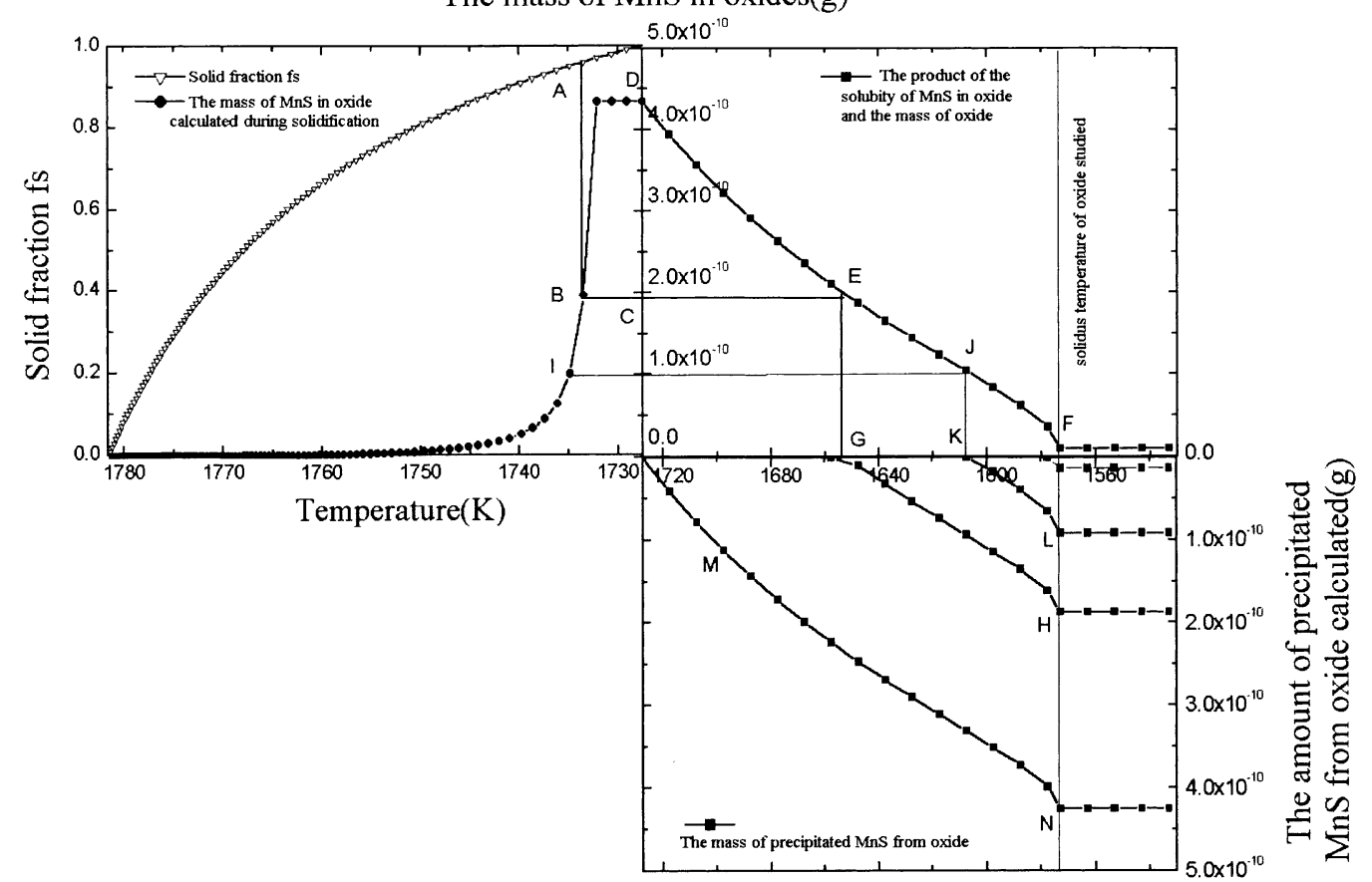

Fig. 4. The precipitation of $\mathrm{MnS}$ from oxides engulfed in solid phase at different temperature versus temperature during solidification.

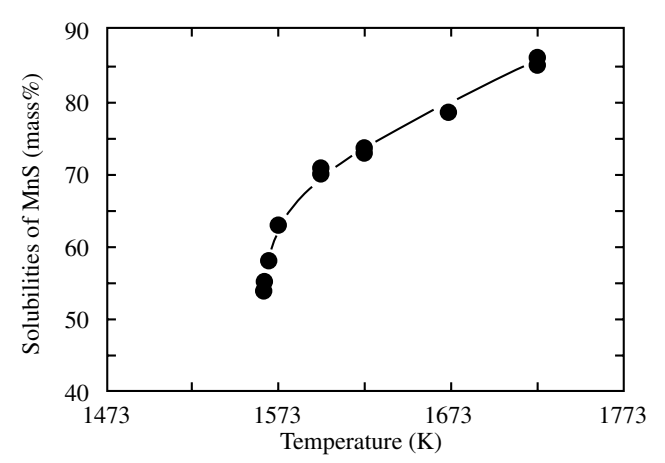

Fig. 5. Solubility of $\mathrm{MnS}$ in the $\mathrm{MnO}-\mathrm{TiO}_{2}$ system as a funtation of temperature from 1565 to $1723 \mathrm{~K}$.

Table 3. Composition of oxides and the solubility of $\mathrm{MnS}$ in oxides studied (in wt $\%$ ).

\begin{tabular}{|c|c|c|c|c|c|c|}
\hline \multirow{2}{*}{ Oxide } & \multicolumn{4}{|c|}{ Composition } & \multicolumn{2}{c|}{ Solubility of MnS } \\
\cline { 2 - 7 } & $\mathrm{Al}_{2} \mathrm{O}_{3}$ & $\mathrm{SiO}_{2}$ & $\mathrm{MnO}$ & $\mathrm{FeO}$ & $\begin{array}{c}\text { At solidus temperature } \\
\text { of steel }\end{array}$ & $\begin{array}{c}\text { At solidus temperature } \\
\text { of oxide (1473K) }\end{array}$ \\
\hline $\mathrm{A}$ & 30 & 30 & 15 & 25 & 70 & 5 \\
\hline $\mathrm{B}$ & 20 & 20 & 40 & 20 & 80 & 15 \\
\hline
\end{tabular}

phase system. According to the reports of N. Sano ${ }^{17)}$ and A. Hasegawa, ${ }^{18)}$ the solubility of $\mathrm{MnS}$ in $\mathrm{MnO}-\mathrm{TiO}_{2}$ melt and $\mathrm{MnO}-\mathrm{SiO}_{2}$ melt as a function of temperature are replotted in Figs. 5 and 6. Based on above relevant reports, the solubility of $\mathrm{MnS}$ in oxide $\mathrm{A}$ and $\mathrm{B}$ at liquidus and solidus temperature are assumed as shown in Table 3. According to N. Sano's report, ${ }^{17)}$ the solubilities of $\mathrm{MnS}$ in molten $\mathrm{MnO}-$ $\mathrm{SiO}_{2}-\mathrm{TiO}_{2}$ system increase with substituting $\mathrm{SiO}_{2}$ with $\mathrm{TiO}_{2}$ in $\mathrm{MnO} \cdot \mathrm{SiO}_{2}$. Due to the optical basicity of $\mathrm{TiO}_{2}$ is higher than that of $\mathrm{SiO}_{2}$, the solubility of $\mathrm{MnS}$ in oxide slag system is assumed to be directly proportional to the sulfide capacity of oxide slag system.

It is assumed that oxide A and B are not engulfed into

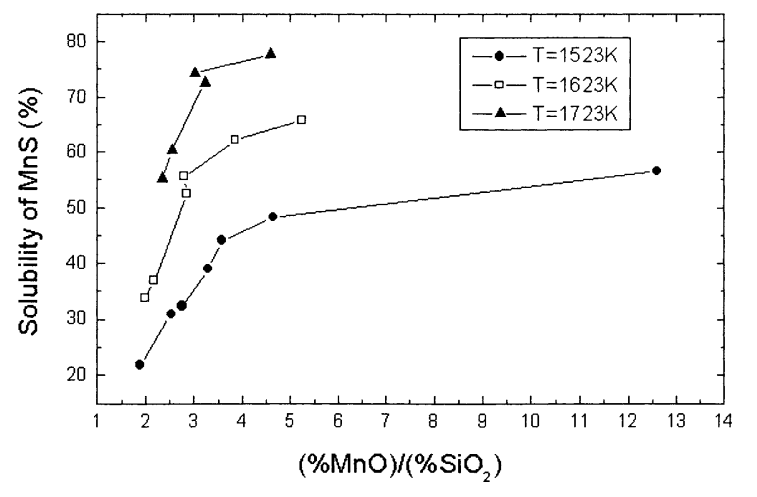

Fig. 6. Solubility of $\mathrm{MnS}$ in the $\mathrm{MnO}-\mathrm{SiO}_{2}$ system.

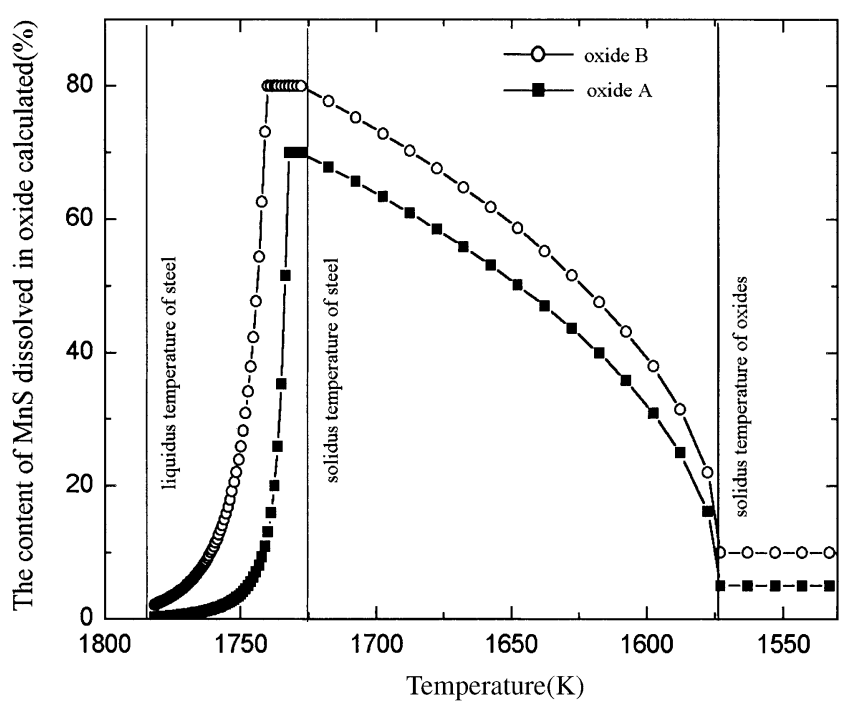

Fig. 7. Comparison of the different content of $\mathrm{MnS}$ dissolved in oxide $\mathrm{A}$ and oxide $\mathrm{B}$ during solidification. 


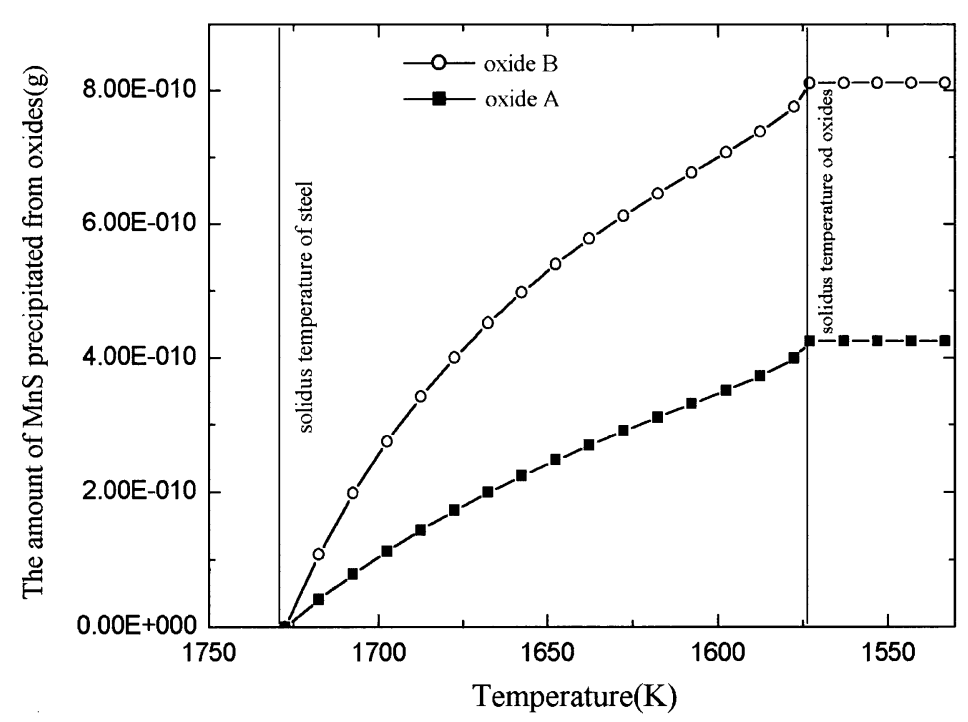

Fig. 8. Comparison of the different amount of MnS precipitated from oxide A and oxide B during solidification.

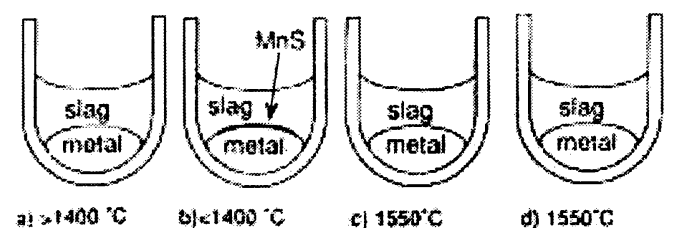

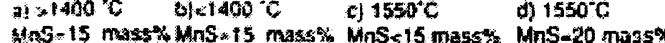

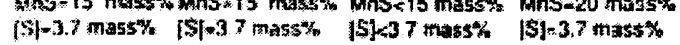

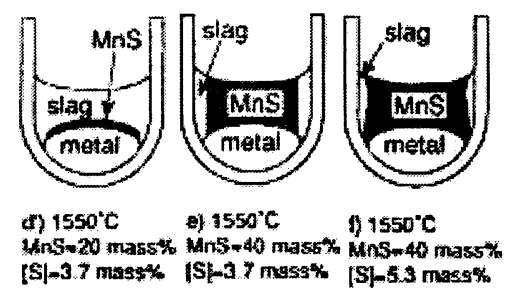

Fig. 9. Precipitation behavior of sulfide at slag/metal interface. ${ }^{19)}$

solid until the end of solidification and the solidus temperature of oxide $\mathrm{A}$ and $\mathrm{B}$ is equal.

The content of $\mathrm{MnS}$ dissolved in oxide $\mathrm{A}$ and $\mathrm{B}$ before oxide solidification is shown in Fig. 7. It is clearly shown that the content of $\mathrm{MnS}$ in oxide $\mathrm{B}$ is higher than that in oxide A since the sulfide capacity of oxide B is higher than that of oxide A. It is also clear that the content of $\mathrm{MnS}$ in oxide B reaches its solubility ahead than in oxide A.

The precipitation of MnS from oxide A and B after steel solidification is shown in Fig. 8. It is clear that the amount of $\mathrm{MnS}$ precipitated from oxide $\mathrm{B}$ is larger than that of oxide A.

\section{Model Validation}

Figure 9 is the reported precipitation behavior of sulfide at slag/metal interface. ${ }^{19)}$ Precipitation of MnS based sulfide under the condition of adding more than 20 mass $\%$ $\mathrm{MnS}$ to the slag was observed to occur at the slag/metal interface. It is clear shown that most of the sulfides precipitate from slag.

The typical oxysulfides found in $\mathrm{Fe}-\mathrm{Si}$ alloy and the analyzed results by EPMA line scanning of $\mathrm{S}$ element are shown in Fig. 10. It is clearly shown that sulfide surrounds

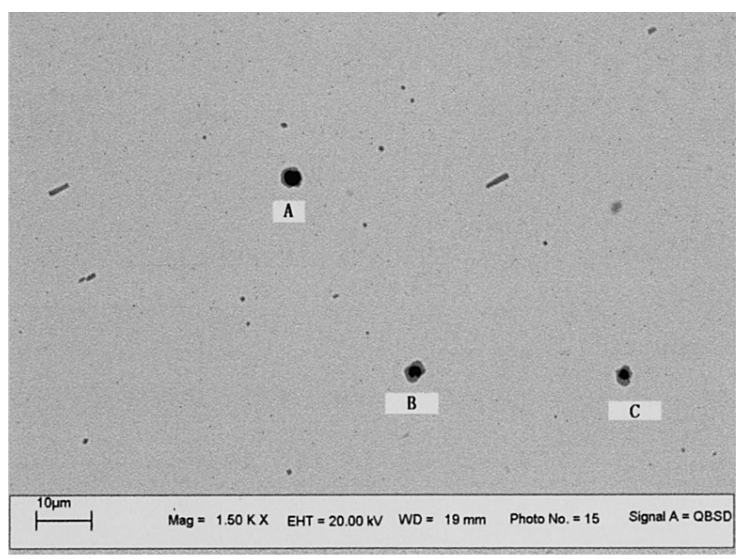

(a)

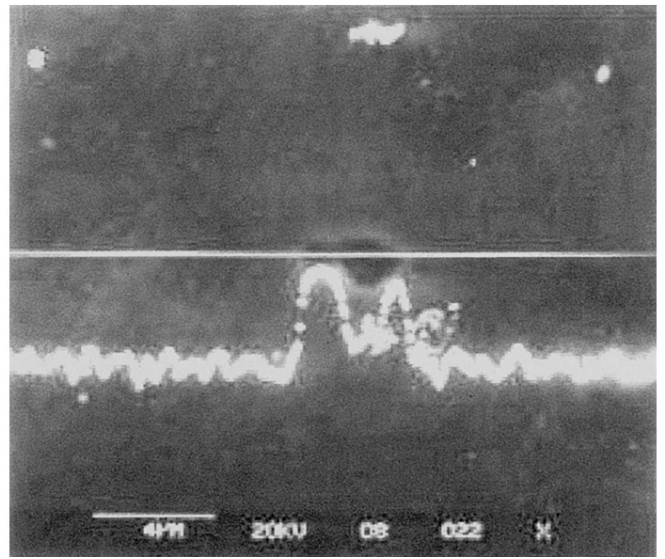

(b)

Fig. 10. Typical SEM image of $\mathrm{MnS}$ particles (A, B and C) precipitated on oxides (a) in $\mathrm{Fe}-\mathrm{Si}$ alloy and the analyzed result by EPMA line scanning of $\mathrm{S}$ element (b).

the oxide and the content of $\mathrm{S}$ in oxide (the core) is higher than that in matrix. The composition of more than 50 oxysulfides' cores are analyzed by EPMA. The relations of the contents of $\mathrm{Al}, \mathrm{Si}, \mathrm{Mn}$ and $\mathrm{Fe}$ versus $\mathrm{S}$ are shown in Fig. 11. It is clear that with the replacement of $\mathrm{Al}_{2} \mathrm{O}_{3}$ and $\mathrm{SiO}_{2}$ 


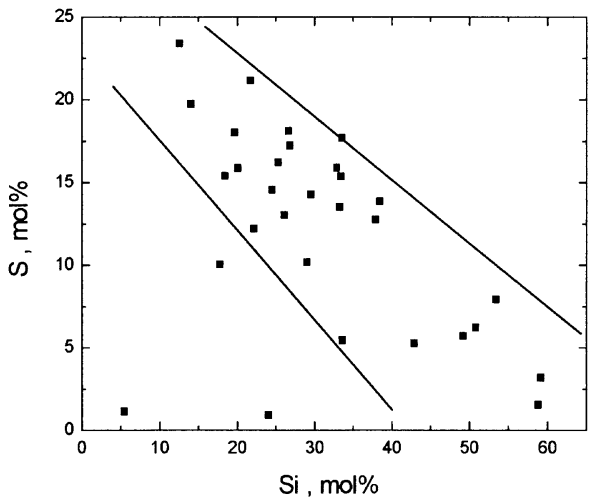

(a)

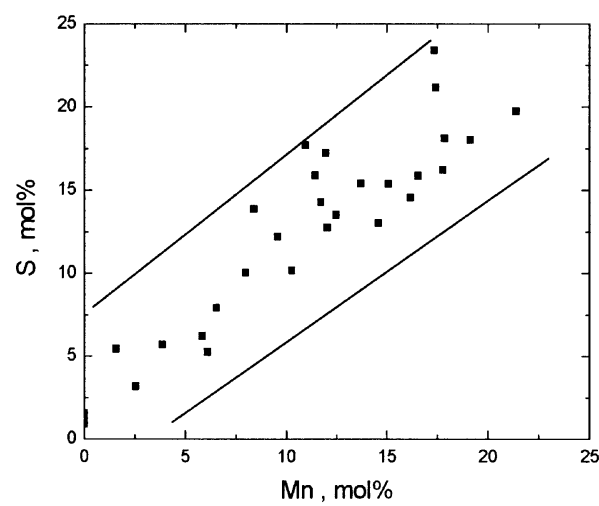

(c)

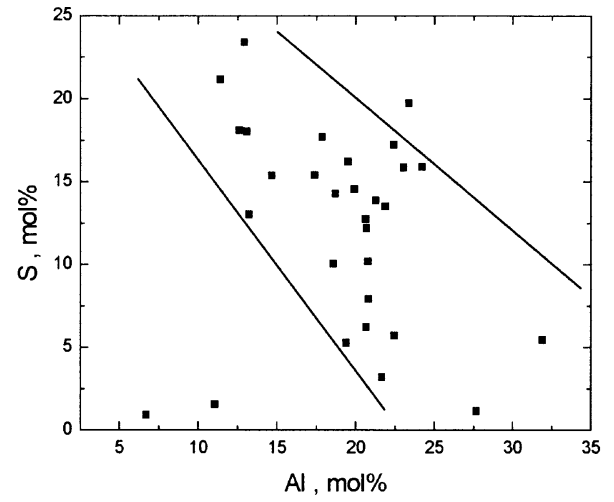

(b)

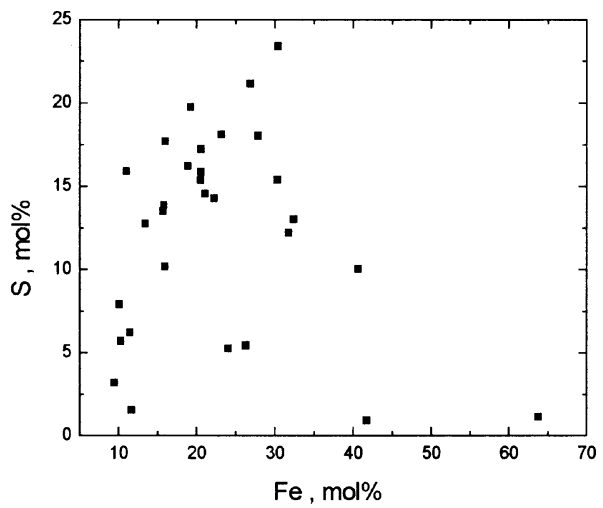

(d)

Fig. 11. S content versus different oxide elements content in the oxides from which sulfides precipitate.

by $\mathrm{MnO}$, the content of $\mathrm{S}$ in oxides increases. Since the optical basicity of $\mathrm{MnO}$ is higher than that of $\mathrm{Al}_{2} \mathrm{O}_{3}$ and $\mathrm{SiO}_{2}$, the sulfide capacity of oxide increases with the content of $\mathrm{MnO}$ increasing.

The relation between the content of $\mathrm{FeO}$ and $\mathrm{S}$ is not very clear. The replacement of $\mathrm{Al}_{2} \mathrm{O}_{3}$ and $\mathrm{SiO}_{2}$ by $\mathrm{FeO}$ will increase the sulfide capacity of oxide, which is helpful for encouraging $\mathrm{S}$ to dissolve in oxide. But the increase of $\mathrm{FeO}$ also means the increase of $a_{[\mathrm{O}]}$, which is harmful to the dissolving of $\mathrm{S}$ in oxide.

\section{Conclusion}

A mathematical model for the solidification of $\mathrm{Fe}-\mathrm{Si}$ alloy is presented. In the model the calculation of microsegregation of solute elements is coupled with the calculation of inclusion precipitation, and the precipitation of oxides and sulfides can be calculated simultaneously.

A mechanism on the precipitation of sulfides on oxides is presented reasonably, in which liquid oxides in molten steel is treated as oxide slag system, optical basicity and sulfide capacity are introduced to calculate the equilibrium distribution ratio of sulfur between liquid oxides and molten steel during solidification.

Based on the presented model, the effect of the composition of oxides on the precipitation of sulfides on oxides is discussed. It is concluded that oxides with low solidus temperature and high sulfide capacity of oxide inclusions will encourage more $\mathrm{S}$ dissolving in oxides and more sulfides precipitated on oxides.

\section{Acknowledgements}

The authors wish to express their thanks to the members of the Institute of Steelmaking, Metallurgical Engineering School, University of Science and Technology Beijing, for support of this work. Special thanks are due to Prof. Jiaquan Zhang and Prof. Junpu Jiang.

\section{REFERENCES}

1) Z. Liu, J. Wei and K. Cai: ISIJ Int., 42 (2002), 958.

2) J. Takamura and S. Mizoguchi: Proc. 6th Int. Iron and Steel Cong., Vol. I, ISIJ, Tokyo, (1990), 591

3) S. Mizoguchi and J. Takamura: Proc. 6th Int. Iron and Steel Cong., Vol. I, ISIJ, Tokyo, (1990), 598

4) S. Ogibayashi, K. Yamaguchi, M. Hirai, H. Goto, H. Yamaguchi and K. Tanaka: Proc. 6th Int. Iron and Steel Cong., Vol. I, ISIJ, Tokyo, (1990), 612.

5) W. Yamada and T. Matsumiya: Proc. 6th Int. Iron and Steel Cong., Vol. I, ISIJ, Tokyo, (1990), 618.

6) D. Lou, K. Cui, X. Wu and J. Zhang: Acta Metall. Sin., 32 (1996), 1027.

7) Z. Ma and D. Janke: ISIJ Int., 38 (1998), 46.

8) Y. Ueshima, K. Isobe, S. Mizoguchi H. Maede and H. Kajioka: Tetsu-to-Hagané, 74 (1988), 465.

9) Y. Ueshima, Y. Sawada, S. Mizoguchi and H. Kajioka: Metall. Trans. A, 20A (1989), 1375

10) Y. Ueshima, S. Mizoguchi, T. Matsumiya and H. Kajioka: Metall. Trans. B, 17B (1986), 845.

11) E. T. Turkdogan: Fundamentals of Steelmaking, The Institute of Materials, Cambridge, (1996), 94.

12) Y. Qu: Principe of Steelmaking, Metallurgical Industry Press of China, Beijing, (1991), 182.

13) M. Wakoh, T. Sawai and S. Mizoguchi: ISIJ Int., 36 (1996), 1014.

14) K. Oikawa, K. Ishida and T. Nishizawa: ISIJ Int., 37 (1997), 332.

15) Z. Ma and J. Dieter: Proc. of the 3rd CAST Annual Conf. of Youths, 
ISIJ International, Vol. 42 (2002), No. 9

China Association for Science and Technology, Beijing, (1998), 46.

16) D. J. Sosinsky and I. D. Sommerville: Metall. Trans. B, 17B (1986), 331 .

17) N. Sano: 2nd Canada-Japan Symp. on Modern Steelmaking and Casting Techniques, The Metallurgical Society of CIM, Toronto,
(1994), 19.

18) A. Hasegawa, K. Morita and N. Sano: Tetsu-to-Hagané, 81 (1995), 1109.

19) H. Sun, R. Ito, K. Nakashima and K. Mori: Tetsu-to-Hagané, 81 (1995), 888 . 